International Journal of Engineering \& Technology, $7(3.13)(2018) 22-26$
International Journal of Engineering \& Technology
WPC

\title{
Two-Wheel Traction Control for Electric Vehicles
}

\author{
Abdelaziz Sahbani ${ }^{1,2}$ \\ ${ }^{1}$ Medina College of Technology Al Madinah Al Munawwarah, Kingdom of Saudi Arabia \\ ${ }^{2}$ Laboratory of Automatic (LARA) \\ National Engineering School of Tunis, Tunis El Manar University \\ BP37, 1002 Tunis, Tunisia \\ *Corresponding author E-mail: abdellazizsahbani@yahoo.fr
}

\begin{abstract}
This paper deals with a detailed dynamic design of traction control strategies based on fuzzy logic controller. The proposed system is motorized by two independent DC motors associated with two static DC converters and an electrical differential. An approach to both longitudinal and lateral controls of two wheels is described. In fact, by using electric motors, it is possible to have a torque control in each wheel drive, enabling the implementation of a traction control. Consequently, the stability and the safety of the vehicle will be improved. Obtained simulation results confirm the efficiency of the proposed controller.
\end{abstract}

Keywords: electric vehicle, DC motors, DC-DC converters, steering angle, traction control, fuzzy logic controller

\section{Introduction}

Nowadays, internal combustion engine vehicles cause many environmental, energy as well as economic problems with the increased cost of petrol. To overcome this difficulty, research is focused on electric vehicles [1-5]. However, the advantages of electric vehicles are not limited to environmental profit: electric motors can control the generated torque with a better dynamic performance, compared with internal combustion engines [2]. Thus, the vehicle stability and safety can be improved, allowing a better performance in limit conditions as compared with traditional cars.

\section{Model of the Traction System}

In this paragraph, is described vehicle dynamics including the forces acting on it. The traction system considered is composed of two static converters and two electric motors. However, the usual vehicle configuration includes only one traction motor driving two wheels and using a differential gear [3]. To reduce the mechanical transmission losses, is substituted, in this work, the mechanical differential gear by an electrical differential with two independent wheel drives. In previous works, similar electric differentials are implemented with PI controllers [7][8]. However, is proposed, in this paper, a control strategy for the two traction motors based on fuzzy logic controller [13].

The two used DC motors, are fed by two DC-DC converters around an IGBT transistors as shown in figure 1, assumed perfect. The two motors and the two DC-DC converters are similar.

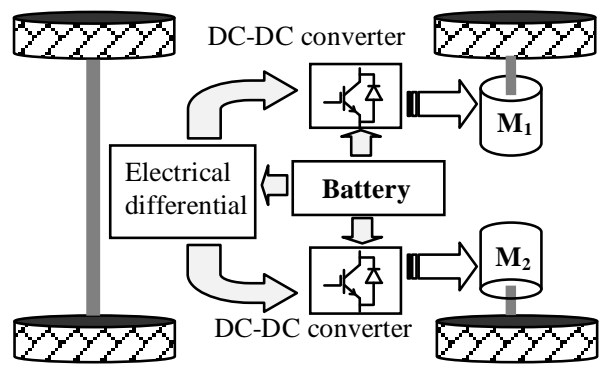

Fig. 1: Elements of the proposed EV structure

\subsection{Model of the DC-DC Converter Coupled With the Traction Motor}

Figure 2 shows a simplified structure of DC-DC converter circuit coupled with DC motor. It consists of a controlled switch ( $S w$ ), a diode $(D)$, a filter inductor $(L)$, a filter capacitor $(C)$ and the DC motor is represented by its equivalent circuit composed by an inductor $\left(L_{M}\right)$, a resistor $\left(R_{M}\right)$ and electromagnetic voltage source $\left(\omega K_{E}\right)$.

The studied DC-DC converter circuit coupled with DC motor has two working topologies corresponding to the switch state. The first topology corresponds to the on state of the switch. In such case, the diode $\mathrm{D}$ is reverse-biased. The dynamic equations of the converter are given by the following equations [11]: 


$$
\left\{\begin{array}{l}
\frac{d i_{L}}{d t}=\frac{v_{i n}}{L}-\frac{v_{o}}{L} \\
\frac{d v_{o}}{d t}=\frac{1}{C} i_{L}-\frac{1}{C} i_{M}
\end{array}\right.
$$

The second topology corresponds to the off state of the switch, Fig.3. For this case, the diode conducts to support an uninterrupted current in the inductor. The dynamic equations of the converter can be expressed as follows:

$$
\left\{\begin{array}{l}
\frac{d i_{L}}{d t}=-\frac{v_{o}}{L} \\
\frac{d v_{o}}{d t}=\frac{1}{C} i_{L}-\frac{1}{C} i_{M}
\end{array}\right.
$$

where $i_{L}$ is the inductor current $v_{\text {in }}$ and $v_{0}$ are respectively the input and the output voltage.

The two mathematical models of the studied converter can be combined in the following general dynamic system:

$$
\left\{\begin{array}{l}
\frac{d i_{L}}{d t}=-\frac{1}{L} v_{0}+\frac{v_{i n}}{L} u \\
\frac{d v_{o}}{d t}=\frac{1}{C} i_{L}-\frac{1}{C} i_{M}
\end{array}\right.
$$

$u$ takes 1 for the on state of the switcher and 0 for the off state and it's controlled with the PWM technique.

The mathematical model of the DC motor is given by

$$
\left\{\begin{array}{l}
\frac{d i_{M}}{d t}=\frac{1}{L_{M}} v_{0}-\frac{R_{M}}{L_{M}} i_{M}-\frac{K_{E}}{L_{M}} \omega \\
\frac{d \omega}{d t}=\frac{f}{J} v_{0}-\frac{K_{M}}{J} i_{M}-\frac{T_{L}}{J} \omega
\end{array}\right.
$$

where $i_{M}$ and $\omega$ are respectively the current and the angular velocity of the motor, $J$ is the global inertia moment, $f$ the viscous friction coefficient, $K_{M}$ the motor torque constant, $K_{E}$ motor voltage constant and $T_{L}$ is the load torque

The choice of the state vector $X=\left[\begin{array}{lllll}i_{L} & v_{0} & i_{M} & \omega\end{array}\right]^{T}$ allows the establishment of the following nonlinear state space representation [12]:

$$
\left\{\begin{array}{l}
\stackrel{\mathrm{g}}{X}=A X+B U \\
\omega=C X
\end{array}\right.
$$

Where:

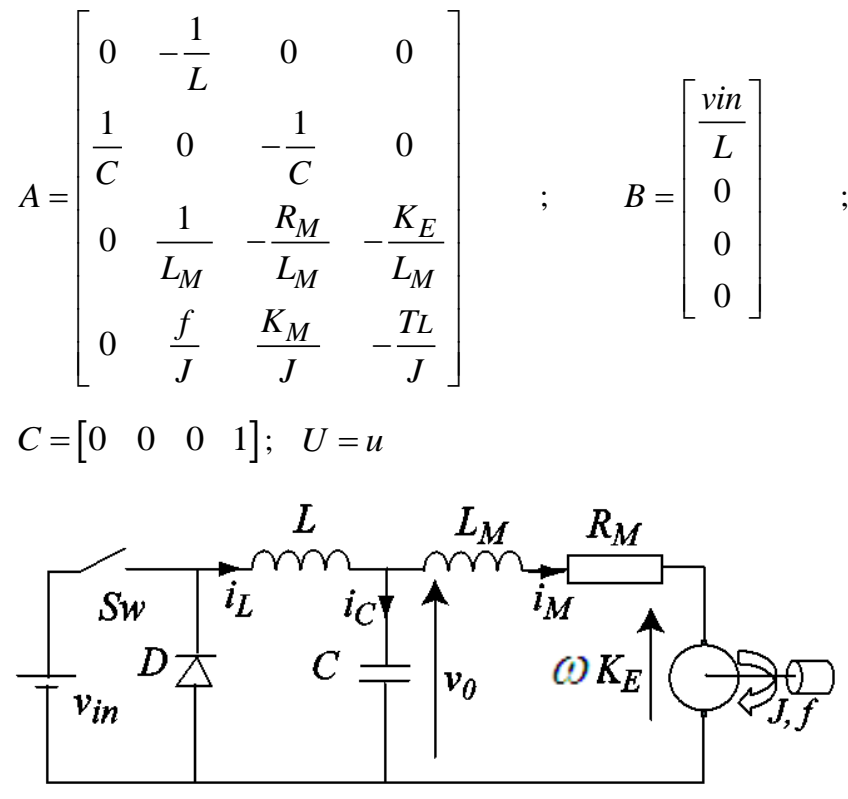

Fig. 2. Structure of the DC converter

\subsection{Vehicle Dynamic}

In this section, is presented the vehicle dynamics including the forces acting on the vehicle, the lateral motion of the vehicle and the wheel drives dynamics.

The environment of the vehicle's evolution produces an equivalent resistance force $F_{\text {res }}$ that depends mainly on climbing resistance, air resistance, rolling resistance, friction resistance [7-10]. In this work, the wheel-road contact is neglected:

$F_{\text {res }}=F_{c}+F_{\text {air }}+F_{v}+F_{r}$

The rolling resistance $F_{r}$ is caused by the tire deformation in contact with the road, $F_{v}$ denotes friction resistance dependent on the vehicle speed. $F_{\text {air }}$ is the resistance of the air acting upon the vehicle: the aerodynamic drag coefficient, depending on the value of the air density, the vehicle frontal area and vehicle velocity. $F_{c}$ is the climbing resistance. These forces are given by equations (7), (8), (9) and (10)

$F_{\text {res }}=m g \sin \alpha$

$F_{\text {air }}=\lambda V^{2}$

$F_{r}=\mu_{r} m g$

$F_{v}=K_{v} V$

$m, g, \alpha, \lambda, \mu_{r}, K_{v}$ and $V$ refer respectively to the total mass of the vehicle, the gravitational acceleration constant, the climbing angle, the aerodynamic coefficient, the rolling resistance coefficient, the Stokes coefficient and the vehicle speed.

The load torque $T_{L}$ is expressed by equation (11), where $r$ is the tire radius and $F_{\text {res }}$ is the resistance forces.

$T_{L}=r F_{r e s}$ 


\subsection{Global model description}

Several descriptions and models for the vehicle are presented in literature [3-10].

In our work, we reduce the mechanical transmission components by substituting the mechanical differential gear by an electrical differential.

Figure 3 presents the vehicle trajectory, when the trajectory is a curve. As well as the distances travelled by each wheel and the wheel speeds are different.

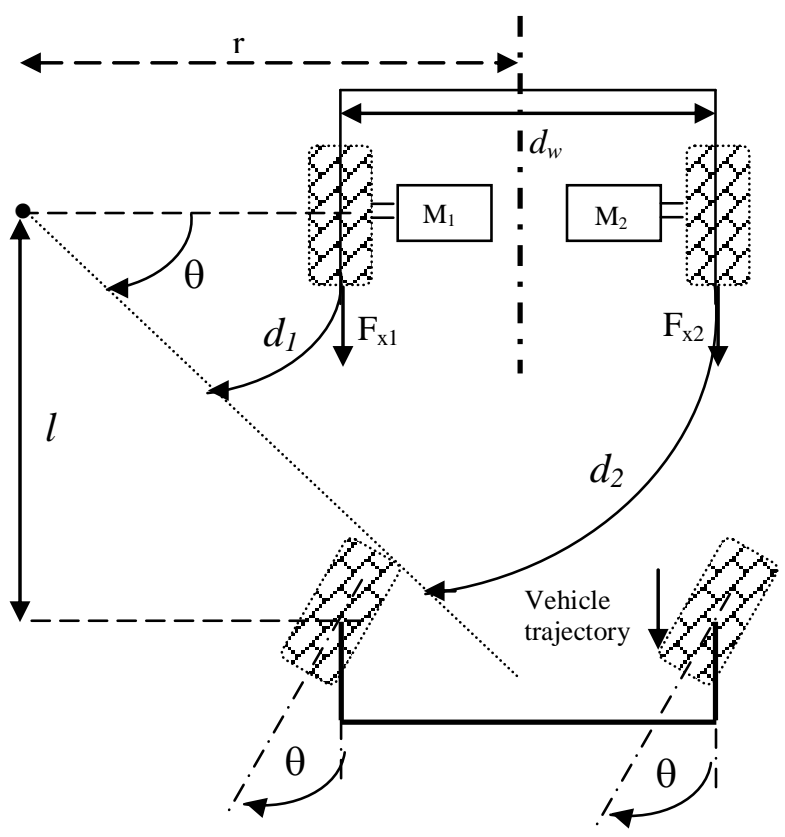

Fig.3. Vehicle trajectory

Referring to fig. 3, the following equations are determined:

$$
\begin{aligned}
& d_{1}=\left(r-\frac{d_{w}}{2}\right) \theta \\
& d_{2}=\left(r+\frac{d_{w}}{2}\right) \theta
\end{aligned}
$$

Where $d_{1}$ and $d_{1}$ are the curved displacements for respectively the right and the left wheels. $r$ is the radius of the curve, $d_{w}$ is the distance between wheels centres along the direction of the axle, and $\theta$ is the steering angle [7-10] .

The radius of the curve can be determined by equations (14) where $l$ is the distance from the front wheel and the rear wheel as shown in figure (3):

$$
r=\frac{l}{\tan (\theta)}
$$

From equations (11) and (12) we notice that $V_{w 1 r e f}$ and $V_{w 2 r e f}$, the linear reference speeds of each wheel drive are function of the angular vehicle speed $\Omega_{\mathrm{v}}$ and the radius of curve.

$$
V_{w 1 r e f}=\Omega_{\mathrm{v}}\left(r+\frac{d_{w}}{2}\right)
$$

$V_{w 2 r e f}=\Omega_{\mathrm{v}}\left(r-\frac{d_{w}}{2}\right)$

The difference between the angular speeds of the right and left wheel drives is expressed by equation (17):

$\Delta \Omega_{\text {wref }}=\Omega w_{1 r e f}-\Omega w_{2 r e f}$

According to equations (14), (15), (16) and (17), the vehicle's motion can be deduced as [10]:

- If $\theta>0$ then $\Delta \Omega_{w}>0$ : the vehicle turns right

- If $\theta=0$ then $\Delta \Omega_{w}=0$ : the vehicle continues straight ahead

- If $\theta<0$ then $\Delta \Omega_{w}<0 \quad$ : the vehicle turns left

When adhesion coefficients on the left and right sides of the vehicle are different, we have to analyse the possible sliding of the vehicle. With the acquisition of these values, the torque on each wheel could be controlled, increasing the steer ability and stability of the vehicle. This is the task of the traction control algorithm described below. The hole model given by figure 4 illustrates both the two wheels model and the electric differential model. In the next part, is described the global model of the fuzzy proposed control.

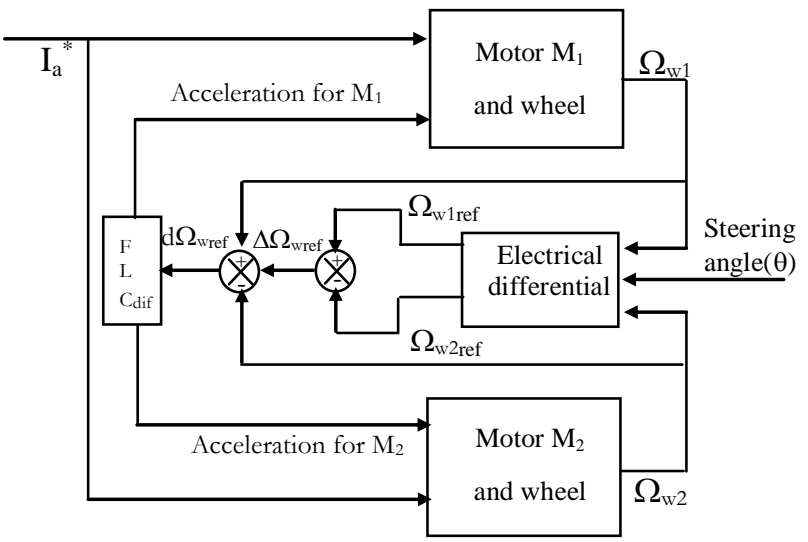

Fig.4 Global model system

\section{Global Structure of the Proposed Control}

In this part, a control strategy is proposed to regulate the wheels speed, according to the architecture given by figure 4 .

In fact, under the same road conditions, wheels roll exactly at same speed when driving straight right. However, if the road conditions under the left and right wheels are different, the traction forces applied to the road surface under the left and right wheels are different (according to equation 6).

Therefore, the vehicle describes a curve, even if the steering angle is maintained at zero. To correct the situation, we have to maintain the relative speed difference between wheels near to zero. This can be achieved by acting in the applied torque to assure that the wheels have exactly the same angular speed when different wheel speeds on left and right are detected. According to equation (12) the difference value ( $\Delta \Omega_{\text {wref }}=\Omega w_{1 r e f}-\Omega w_{2 r e f}$ ) is calculated first by the electrical differential and then summed with the two- 
wheel's real difference to form $d \Omega_{w r e f}$. Finally, this information will be given to the Fuzzy Logic Controller to obtain the required accelerations on both sides. The inference rules of the described controller are summarized in the in table 1.

Table1 . Inference matrix for the described controller

\begin{tabular}{|c|c|c|c|c|c|}
\hline \multirow{ynnnnn}{yyn}{} & $\mathrm{e}$ & $\mathrm{BN}$ & $\mathrm{Z}$ & $\mathrm{P}$ & $\mathrm{BP}$ \\
\cline { 1 - 5 } $\mathrm{BN}$ & $\mathrm{BN}$ & $\mathrm{N}$ & $\mathrm{N}$ & $\mathrm{N}$ & $\mathrm{P}$ \\
\hline $\mathrm{N}$ & $\mathrm{BN}$ & $\mathrm{N}$ & $\mathrm{Z}$ & $\mathrm{Z}$ & $\mathrm{P}$ \\
\hline $\mathrm{Z}$ & $\mathrm{N}$ & $\mathrm{N}$ & $\mathrm{Z}$ & $\mathrm{P}$ & $\mathrm{P}$ \\
\hline $\mathrm{P}$ & $\mathrm{N}$ & $\mathrm{Z}$ & $\mathrm{Z}$ & $\mathrm{P}$ & $\mathrm{BP}$ \\
\hline $\mathrm{BP}$ & $\mathrm{N}$ & $\mathrm{P}$ & $\mathrm{P}$ & $\mathrm{P}$ & $\mathrm{BP}$ \\
\hline
\end{tabular}

Now, the motors accelerations deduced by the first fuzzy controller are given respectively to the second fuzzy logic controllers on each side right and left, which ensures the motor's current control. The global structure of the current control is illustrated by fig.5.

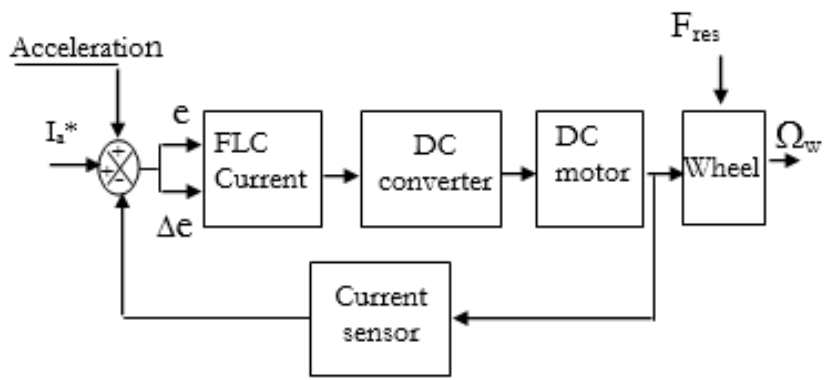

Fig.5. Current control bloc for one side

The regulator (FLC current) is implemented on both, right and left side of the vehicle. Table 2 gives the inference matrix of this fuzzy controller

Table 2. Inference matrix for the fuzzy controller

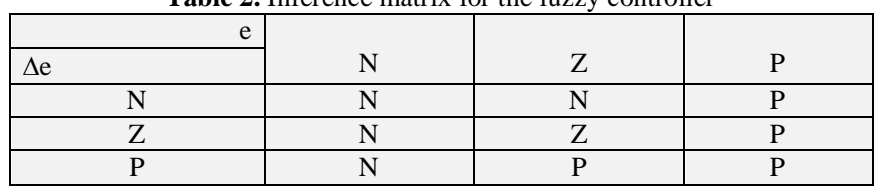

\section{Tests and Simulation Results}

In a first time, we have varied the steering angle $\square$ as shown in figure 6 and we have studied the behaviour of the two wheels speed. Figures 7 and 8 show respectively the left and the right wheel's speed responses by the variation of the steering angle.

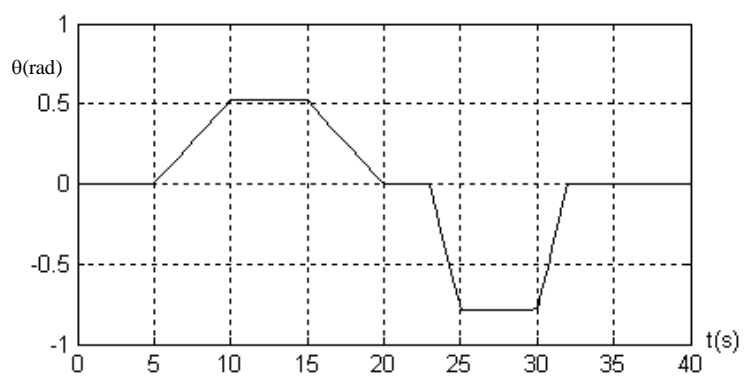

Figure 6. Steering angle variation

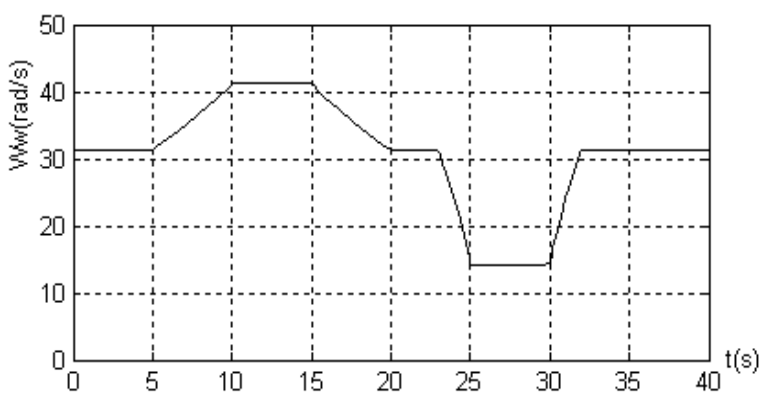

Fig7. Left wheel's speed response

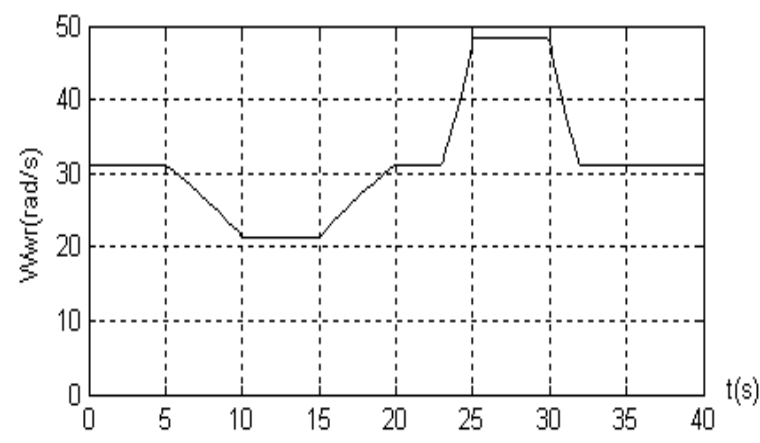

Fi 8. Right wheel's speed response

According to the presented situation, the controller (FLCdif) has detected a non-zero value in the difference of the two wheels speeds and then it reacts imposing corresponding speeds: when the steering angle reaches nonzero values. The electrical differential imposes different speed reference values for the two wheels (initially set to the same speed value). The controller detects the difference between the two wheels speeds and gives an acceleration to increase the speed in the right wheel and decrease it in the left one and vice versa.

Next, to assure that the wheels have exactly the same angular speed, we look the behaviour of the two wheels if the right wheel is under a high load. The steering angle is maintained at zero value. In this situation, the control strategy increases the torque on the right wheel and reduces it in the left one, in order to keep them at the same speed, by maintaining the global torque constant. Figures 9 and 10 show respectively the left and the right wheel speeds. The currents absorbed by each wheel are respectively shown in figure 11 and 12.

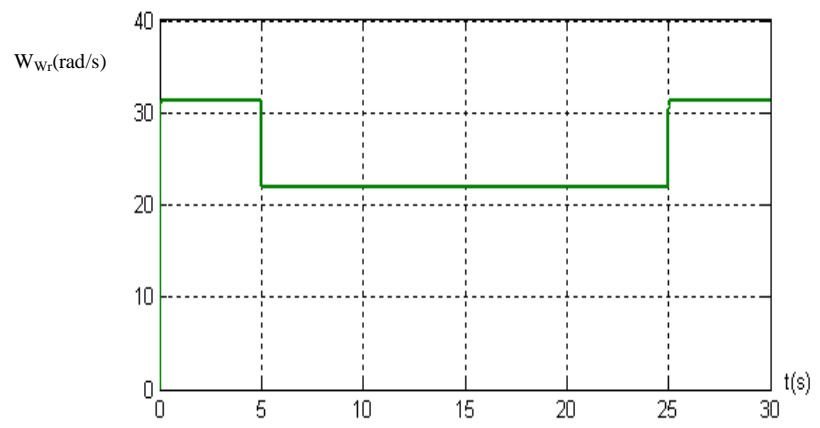

Fig 9. Left wheel speed 


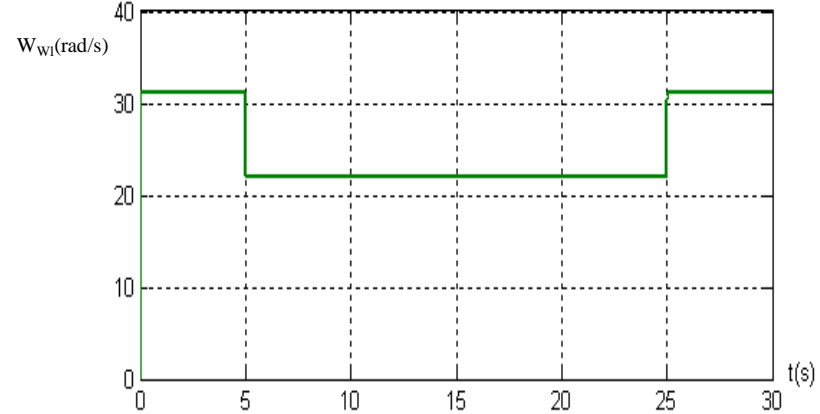

Fig 10. Right wheel speed

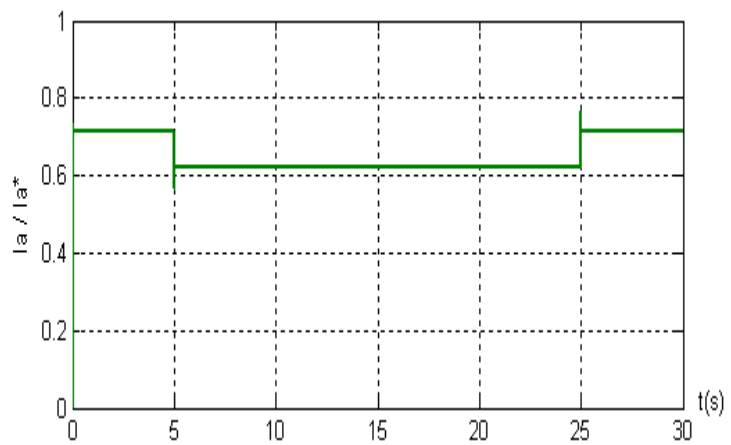

Fig 11. Current absorbed by the left wheel

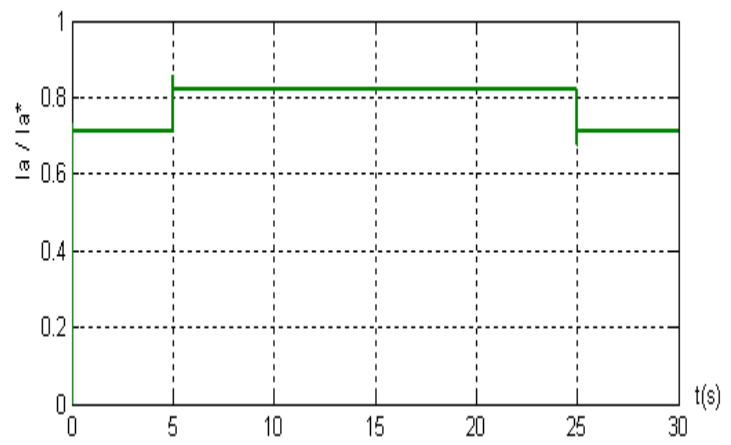

Fig 12. Current absorbed by the right wheel

\section{Conclusion}

This paper presented an electric vehicle with two independent wheel drives. An electrical differential was implemented assuring that, the two wheels roll at the same speed in straight right trajectory. In slopes, the difference between the two speeds was controlled to allow a vehicle trajectory without sliding. The system analysis, and simulation is presented in the paper and therefore, a fuzzy logic controller was implemented as a solution.

The simulation results prove that the vehicle motion remains stable without sliding. These results show the efficiency of the proposed non-conventional controller.

On the other hand, the use of the electrical differential improves the traction control system without the use of any substantial extra mechanical incorporation.

\section{References}

[1] V. Delli Colli, G. Tomassi, and M. Scarano, Single Wheel Longitudinal Traction Control for Electric Vehicles, IEEE Transactions on Power Electronics, vol.21, n³, pp.709-808, May 2006.
[2] B. Gasbaoui, A. Chaker, A. Laoufi, B. Allaoua and A. Nasri, The Efficiency of Direct Torque Control for Electric Vehicle Behavior Improvement, Serbian Journal of Electrical Engineering, vol. 8, $\mathrm{n}^{\circ} 2$, pp. 127 - 146, May 2011.

[3] S. Sakai, H. Sado, and Y. Hori, Novel skid avoidance method without vehicle chassis speed for electric vehicle, in Proc. Of the International Power Electronics Conference (IPEC), vol. 4, pp. 19791984, Tokyo, 2000.

[4] G. Sinclair, A. Cruden, J. McDonald and B. Hredzak, Electronic differential with sliding mode controller for a direct wheel drive electric vehicle, Mechatronics, ICM '04, Istamboul, 2004.

[5] S. H. Ding, L. Liu and W. X. Zheng, Sliding mode direct yawmoment control design for in-wheel electric vehicles, vol. 64, ${ }^{\circ} 8$, pp. 6752-6762, Mars 2017.

[6] M. Yildirim, E. Oksuztepe, B. Tanyeri and H. Kurum, Electronic differential system for an electric vehicle with in-wheel motor, in Proc. Of the $9^{\text {th }}$ International Conference on Electrical and Electronics Engineering (ELECO), pp. 1048-1052, 26-28 Nov. 2015.

[7] D. Foito, A. Roque, J. Esteves and J. Maia, Electric Vehicle with Two Independent Wheel Drives : Improving The Performance with a Traction Control System, in Proc. of the EVS 17, Montreal, 2000.

[8] A. Cordeiro, D. Foito and M. Guerreiro, sensolrless speed control system for an electric vehicle without mechanical differential gear, in Proc of the IEEE Mediterranean Electrotechnical Conference MELECON 2006, pp. 1174-1177, 2006.

[9] S. M. Wasfy, M. M.Eissa, G. M.A. Sowilam and M. Abdel Monem, Modeling and Analysis of a Traction Control System for Two Independent Wheel Drives-Eclectic Vehicle, in Proc of the International Conference on Renewable Energies and Power Quality (ICREPQ'10), Granada (Spain), 23 - 25 March, 2010.

[10] A. Draou, Electronic differential speed control for two in-wheels motor drive vehicle, in Proc of the $4^{\text {th }}$ International Conf. Power Engineering Energy and Electrical Drives, pp. 764-769, May 2013.

[11] K. Ben Saad, A. Sahbani and M. Benrejeb, Design Procedure and Implementation of a Robust Fuzzy Sliding Mode Controller for Buck Converters, in proc of the International Review of Automatic Control (IREACO), vol.1, n³, pp. 303-310, September 2008.

[12] L. Flores and H. Sira-Ramfrez, DC motor velocity control through a DC-to-DC power converter, in Proc of the $43^{\text {rd }}$ IEEE Conference on Decision and Control, pp. 5297-5302, December 2004.

[13] H. Kahveci, H.I. Okumus and M. Ekici, An electronic differential system using fuzzy logic speed controlled in-wheel brushless DC motors, in Proc of the IEEE 4th International Conference on Power Engineering Energy and Electrical Drives (POWERENG), pp. 881 885, May 2013. 